\title{
Recent abnormal hydrologic behavior of Tibetan lakes inferred from multi-mission altimetry and its driving force analyses
}

\author{
Pengfei Zhan ${ }^{1}$, Chunqiao Song ${ }^{2}$, Jida Wang ${ }^{3}$, Wenkai Li ${ }^{4}$, Linghong KE ${ }^{5}$, Kai Liu ${ }^{1}$, and \\ Tan Chen ${ }^{1}$ \\ ${ }^{1}$ Nanjing Institute of Geography and Limnology Chinese Academy of Sciences \\ ${ }^{2}$ Nanjing Institute of Geography and Limnology, Chinese Academy of Sciences \\ ${ }^{3}$ Kansas State University \\ ${ }^{4}$ Nanjing University of Information Science and Technology \\ ${ }^{5}$ Hohai University College of Hydrology and Water Resources
}

June 22, 2020

\begin{abstract}
The inland lakes in the Tibetan Plateau (TP), with closed catchments and minimal human disturbance, are important indicators to climate change. However, examination of the spatiotemporal patterns of the Tibetan lake changes, especially for water level variation, was usually limited by inadequate measurement accessibility. This obstacle has been remedied by the developing satellite altimetry observations. The more recent studies revealed the growth tendency of lakes in the central TP had been decelerated or reversed during the period 2010-2016. It has not been systematically investigated whether the deceleration or hiatus would last in the following years thus far. This study aims to combine the traditional and recently-advanced altimetry observations to update our understanding of Tibetan lake changes in recent years. The results reveal that water level changes of the 22 examined lakes showed abrupt rises during the period 2016-2018, but the onsets and magnitudes of the rises varied among the lakes. During the study period, the water level of the nine lakes in the northern TP displayed a drastic rising trend with an average rate of $0.82 \mathrm{~m} / \mathrm{a}$. In the central TP, the lake level changes were generally divided into two categories. The water levels for the lakes in the western CTP rose rapidly, while in the eastern CTP, the lake water levels rose slowly with an average rising rate less than $0.40 \mathrm{~m} / \mathrm{a}$. The water levels for lakes in the northeastern TP and northwestern TP kept a stably rising tendency. According to the results of climate analysis, the spatial differences of the lake level rise rates were primarily caused by the spatial and temporal changes of precipitation over the TP, which may be related to the large-scale atmospheric circulation affected by the El Niño and La Niña events.
\end{abstract}

\begin{abstract}
:
The inland lakes in the Tibetan Plateau (TP), with closed catchments and minimal human disturbance, are important indicators to climate change. However, examination of the spatiotemporal patterns of the Tibetan lake changes, especially for water level variation, was usually limited by inadequate measurement accessibility. This obstacle has been remedied by the developing satellite altimetry observations. The more recent studies revealed the growth tendency of lakes in the central TP had been decelerated or reversed during the period 2010-2016. It has not been systematically investigated whether the deceleration or hiatus would last in the following years thus far. This study aims to combine the traditional and recently-advanced altimetry observations to update our understanding of Tibetan lake changes in recent years. The results reveal that water level changes of the 22 examined lakes showed abrupt rises during the period 2016-2018, but the onsets and magnitudes of the rises varied among the lakes. During the study period, the water level of the nine lakes in the northern TP displayed a drastic rising trend with an average rate of $0.82 \mathrm{~m} / \mathrm{a}$. In
\end{abstract}


the central TP, the lake level changes were generally divided into two categories. The water levels for the lakes in the western CTP rose rapidly, while in the eastern CTP, the lake water levels rose slowly with an average rising rate less than $0.40 \mathrm{~m} / \mathrm{a}$. The water levels for lakes in the northeastern TP and northwestern TP kept a stably rising tendency. According to the results of climate analysis, the spatial differences of the lake level rise rates were primarily caused by the spatial and temporal changes of precipitation over the TP, which may be related to the large-scale atmospheric circulation affected by the El Niño and La Niña events.

Key words : Tibetan Plateau, lake, water level, satellite altimetry, climate change, precipitation

\section{Introduction}

Lakes are an important part of global hydrological and biogeochemical cycles, as well as an essential resource for human societies (Lehner and Döll 2004; Palmer et al. 2015; Sheng et al. 2016). These inland waterbodies are quite sensitive to climate change and human activities. The last several decades have witnessed the widespread and tremendous changes in lakes in the context of global changes at regional and global scales (Shi et al. 2014; Smith et al. 2005; Song et al. 2013; Vörösmarty 2002; Wang et al. 2014). Lake changes have profound effects on regional water balance, ecosystems, biogeochemical cycles, exchange of energy and tracing gases with the atmosphere, and human water consumption. Therefore, investigation of lake variability is critical for a wide range of socioeconomic, political, and scientific interests. Several recent efforts such as Pekel et al. (2016), Donchyts et al. (2016), Yao et al. (2019), and Busker et al. (2019) elucidate lake dynamics at global scale using multi-temporal satellite optical and altimetry observations. The prominent characteristics revealed in these studies suggest that many large lakes, such as Caspian Sea, Aral Sea, Urmia Lake in endorheic basins of Eurasian hinterland, shrank remarkably in the near decades(Wang et al. 2018). On the contrast, widespread lake growths are observed on Earth's highest plateau, the Tibetan Plateau (TP).

The TP, known as "Asian Water Tower", accommodates vast distributions of glaciers and lakes. There are more than 1200 lakes larger than $1 \mathrm{~km}^{2}$, covering an inundation area of $\sim 43,000 \mathrm{~km}^{2}$ (recorded around 2000) (Zhang et al. 2014). The lack of historical in situ data in the remote and sparsely populated TP has greatly limited the investigation of the hydrological and climate responses of lakes to the changing climate. However, this obstacle has been reduced by the rapidly emerging satellite observations from various sensors. Many prior studies employed optical satellite images to examine lake changes across space and time in the TP (Huang et al. 2011; Lei et al. 2014; Lu et al. 2017; Mao et al. 2018; Qiao et al. 2019; Song et al. 2014a; Song et al. 2014b; Wan et al. 2016; Zhang et al. 2019; Zhu et al. 2010). However, the acquisition of high-quality optical images is usually impeded by unfavorable weather conditions, and the derived lake area variations cannot directly indicate the water budget changes. Therefore, more and more satellite altimetry measurements have been synergized for the investigation of the lake dynamics across the TP.

Phan et al. (2012), Song et al. (2014b), Wang et al. (2013), and Zhang et al. (2011) have examined the changes in the lake water levels in the TP and found that most Tibetan lakes experienced rapid water level rises during 2003-2009 by using the Ice, Cloud and land Elevation Satellite (ICESat) laser altimetry data. However, the long revisit cycle and sparse sampling of the ICESat mission is insufficient for tracing longterm or abrupt changes (e.g. sudden shift) in water level, resulting in an incomplete misunderstanding of the trends and heterogeneous characteristics of lake changes in the TP. Favorably, the height measurements of satellite radar altimeters that have been launched continuously since the early 1990s can extend lake level observations to a longer temporal coverage. The advantages are applications that are not affected by weather and a reasonable high frequency of revisit from monthly to ten-day time scales, so that we can better solve the spatial and temporal patterns of water level changes and driving mechanisms in the TP. The combination of multi-radar altimetry missions, including TOPEX/POSEIDON, ERS-1/-2, Envisat, Cryosat-2 and Jason$1 /-2 /-3$, at the height accuracy ranging from decimeters to centimeters, have been used to investigate the decadal water level changes of lakes in the TP (Gao et al. 2013; Kleinherenbrink et al. 2015; Song et al. 2015a). However, these radar altimeters are only suitable for large water bodies and because of their large-size footprint and along-track/cross-track spacing, many lakes are only accessible by one or two satellites. 
The recent advances in satellite altimeters, e.g. CryoSat-2 (2010-), SARAL/AltiKa (2013-), Jason-3 (2016-) and Sentinel-3 (2016-), provide alternative options of measuring relatively smaller water bodies. The more recent studies benefiting from the longer and finer observations revealed the growth tendency of lakes in the central TP had been decelerated or reversed during the period 2010-2016 (Hwang et al. 2019; Jiang et al. 2017; Lei et al. 2019; Song et al. 2015b). However, whether the deceleration or hiatus would last in the following years remains unclear. It has not been systematically investigated thus far. Thus, this study aims to combine the traditional and recently-advanced radar altimetry measurements to update our understanding of the changing characteristics of Tibetan lakes in the near past several years. Furthermore, we will explore the potential climate driving mechanism of the recent varying tendency of lake changes in the TP.

\section{Materials and methods}

\subsection{Study region}

The TP is located in central Eurasia with a geographic area about 3 million km2 (Song et al. 2014b). It has a mean altitude of approximately 4,000 $\mathrm{m}$. The climate in the TP is marked by low temperature and strong solar radiation (Piao et al. 2011). The precipitation in the TP is characterized by strong seasonality. Most of the precipitation ( $60 \%-90 \%$ of annual total precipitation) occurs between June and September, while the rainfall from November to February is less than 10\%. (Xu et al. 2008). The TP and its surroundings are sometimes known as "Earth's Third Pole" and "Water Tower of Asia" because of the the rich storage of water resources. The geographical environment of this area is complex, and the water system is developed. It is the birthplace of many large rivers (Yangtze River, Yellow River, Mekong River, etc.) in China and throughout Asia. In addition, there are many lakes in the TP, which is one of the most densely distributed regions in China, and these lakes are currently undergoing significant changes due to the impact of climate changes (Ma et al. 2010). In this study, a total of 22 lakes larger than $100 \mathrm{~km} 2$ in the TP were analyzed by combining the traditional and recently-advanced radar altimetry measurements. The characteristics of the studied 22 TP lakes covered by satellite altimetry are presented in Fig. 1 and Table 2.

\section{[Insert Figure 1 here]}

\subsection{Study data}

\subsubsection{LEGOS Hydroweb and DAHITI altimetry data archives}

Observation data provided by altimetry satellites has been gradually increased since the early 1990s, including TOPEX/POSEIDON(T/P), ERS-1, ERS-2, Jason-1/-2/-3, Envisat and Cryosat-2(Table 1). The combination of different altimetry satellites can increase the spatial coverage of altimetry measurements and extend the temporal span to nearly thirty years. At present, the long-term lake level changes reconstructed by many institutions is based on the altimetry satellite data of different service years. As one data source of our analyzed water levels, we obtained lake levels from the Laboratoire d Etudes en Geophysique et Oceanographie Spatiales (LEGOS) Hydroweb altimetry data archive and the Hydrological Time Series of Inland Waters (DAHITI) altimetry data archive. The LEGOS Hydroweb altimetry data archive was derived from merged Topex/Poseidon, Jason, Envisat and Sentinel data (Cretaux et al. 2009; Cretaux et al. 2011b). All background rectification have been used to produce this data archive. Since different altimetry satellites are used for the same lake, the water level calculation is mainly divided into three steps. First, each satellite data was processed separately to obtain the altimetry measurement data of different satellites, and then Topex/Poseidon data was used as a reference standard to minimized potential radar instrument deviations and geoid differences between different satellites. Finally, lake levels from the different satellites were merged. The DAHITI data archive was launched by the Deutsches Geodatisches Forschungsinstitut (DGFI, now DGFI-TUM) in 2013. The processing procedure of DAHITI database in detail can be referred to in Schwatke et al. (Schwatke et al. 2015) which was based on an extended outlier detection and a Kalman filtering of multi-source merged altimetry measurements. In this paper, because the algorithms adopted by 
the two data archives were different, we only used one of them for a lake. When a lake was covered by the two data archives at the same time, Hydroweb data archive was selected as the priority.

\section{[Insert Table 1 here]}

Both two data archives cover a certain number of lakes in the Tibetan Plateau (Table 2). The long-term water level change information of 16 lakes was obtained based on Hydroweb and DAHITI data archives. However, the number of lakes cannot fully meet the needs of our lake level monitoring (refer back to Fig. 1). Therefore, in this study, SARAL and Sentinel-3 altimetry data were used to supplement the missing observations from the LEGOS Hydroweb and DAHITI data archives. We interpreted and combined SARAL and Sentinel-3 altimetry data to obtain a total of 12 lake level time series during the period 2013-2018. Six of them, covering the same lakes as Hydroweb and DAHITI data archives, were used to verify the reliability of SARAL and Sentinel-3 altimetry data. Others were used as the data supplement.

\subsubsection{Supplementary altimetry data}

\subsubsection{SARAL/AltiKa data}

SARAL is a common mission of the Indian Space Research Organization (ISRO) and the France space agency (Project 2010). The mission, launched on 25 February 2013, is a continuation of the ERS series and Envisat missions. The orbit and revisit cycle of SARAL satellite were the same as Envisat, but after July 2016, SARAL satellite was then transformed to drifting ground track mode. Compared to the previous altimetry satellites, the improvement of SARAL/AltiKa was that it was the first altimeter to measure in the Ka band, with higher spatial resolution. In addition, AltiKa's bandwidth (500 MHz) had been enhanced, which resulted in a higher vertical resolution and higher pulse repetition frequency (Project 2010). We downloaded the SARAL data (spanning from March 2013 to June 2016) from ftp://avisoftp.cnes.fr.

\subsubsection{Sentinel-3/SRAL data}

The Surface Topography Mission uses the Synthetic Aperture Radar Altimeter (SRAL) instrument, which transmits pulses occasionally at $\mathrm{Ku}$ band for altimeter range measurements, supplemented by a C-band frequency to correct range delay errors. The SRAL instrument acquires data in two measurement modes, the Low-Resolution Mode (LRM) which is useful over homogeneous open-ocean surfaces, and the Synthetic Aperture Radar (SAR) mode which achieves high along-track resolution over relatively flat surfaces. Sentinel-3 satellite has multiple new functions and modes with the dual-frequency SAR radar altimeter (SRAL) (Donlon et al. 2012). Among them, the tracking mode is the most critical characteristic(Jiang et al. 2019). We downloaded the needed data from March 2016 to December 2018 through https://sentinel.esa.int/web/sentinel/ sentinel-data-access.

\section{[Insert Table 2 here]}

\subsubsection{Climate data}

To investigate the climate impact of lake water level changes, the annual and monthly precipitation data for the period 1990-2018 from 10 stations in the TP was collected from the China Meteorological Network (http://data. cma.cn). The locations of the ten stations are shown in Fig. 1. In addition, we analyzed the changes of water vapor transport modes over the TP and its surroundings based on ERA-interim reanalysis data with a spatial resolution of $0.75 \mathrm{degx} 0.75 \mathrm{deg}$ (Dee et al. 2011). The sea surface temperature (SST) from the National Oceanic and Atmospheric Administration was also applied to investigate the association of the TP lake level changes and precipitation anomalies driven by El Nino and La Nina events.

\subsection{Methods}

2.3.1 Altimetry water level processing 
We retrieved important variables such as time, latitude, longitude, water level elevation, and geoid from the collected raw data files. Since the parameter information contained in each altimeter satellite is not completely consistent, the formulas for calculating water level are also not the same. Thus, this part of the work also needs to refer to the data manual for each altimeter satellite. We calculated water levels by the following the formula below (Hwang et al., 2016):

$H_{\text {water }}=h_{\text {sat }}-R_{\text {alt }}-C(1)$

where $H_{\text {water }}$ refers to ellipsoidal height of the waterbody, $h_{\text {sat }}$ refers to ellipsoidal height of the satellite, $R_{\text {alt }}$ refers to distance between satellite and waterbody, and $C$ refers to the integration of all corrections. Considered corrections include inverted barometer height correction $\left(C_{\text {inv }}\right)$, wet and dry tropospheric corrections $\left(C_{\text {wet }}, C_{\text {dry }}\right)$, ionospheric correction $\left(C_{\text {iono }}\right)$, solid earth tide $\left(C_{\text {solid }}\right)$, ocean earth tide $\left(C_{\text {ocean }}\right)$, poletide $\left(C_{\text {pole }}\right)$, sea state bias correction $\left(C_{\mathrm{stb}}\right)$, and high frequency fluctuations correction $\left(C_{\mathrm{hf}}\right)$.

\subsubsection{Removal of measurement outliers}

For all lakes, the original tracks of the satellite are observed as it passes through the lake, then the track data falling within the lake will be selected. As the observations contain outliers, it is necessary to eliminate them for subsequent work. Outlier elimination for the selected orbit data was divided into two steps.

Step 1: Apply a median filter with a six-month window size to smooth the original time series during the study period, and remove the outliers out of two standard deviations from the median for all the measurements.

Step 2: Remove the data other than twice the standard deviation for single-day measurements.

\subsubsection{Unifying the reference system of different altimetry sources}

In order to reduce the differences caused by different altimeter instruments, all lake levels from multisource altimetry satellite were first converted to the same geographic reference system. The system biases calculated by the data from different altimetry satellites at the same period was subtracted from the elevation measurements for each lake (Cretaux et al. 2011a; Jarihani et al. 2013).

\section{Results and discussions}

\subsection{Long-term lake level variations based on Hydroweb and DAHITI data archives}

The best way of altimetry data validation is to compare the altimeter-derived lake level with the in situ data. At present, only a few lakes such as Qinghai Lake and Nam Co have long-term continuous water level observations in the TP which are extremely limited compared with more than 1,200 lakes $\left(>1 \mathrm{~km}^{2}\right)$ across the TP (Zhang et al. 2014). The altimetry data archives, such as Hydroweb and DAHITI, play an critical role in verifying the lake level changes obtained by other satellite altimetry data. In order to verify the reliability of Hydroweb and DAHITI altimetry data archives, the annual means of water level for Qinghai Lake was validated against the in situ water levels measured by the hydrological station. As shown in Fig. 2 , the altimetry levels follow a robust linear correlation with in situ measurement, with a R2 value of 0.90 . This agreement indicates that the lake level time series obtained from Hydroweb and DAHITI have a high reliability, and therefore, were used as a reference for validating our level time series processed from SARAL and Sentinel-3 altimeters.

\section{[Insert Figure 2 here]}

Fig. 3 presents the time series of water level for eight large TP lakes from Hydroweb and DAHITI data archives from the 1990s to 2018. All of the eight lakes showed rapid water level increase since around 2000. In comparison, the abrupt changing points varied with different lakes. For example, the lake level for Seling Co, Nam Co, Nganze Co and Tangra YumCo began to rise rapidly before 2000, while Migriggyangzham Co and Qinghai Lake began to grow rapidly after 2003 and 2005, respectively. The most dramatic expansion occurred in Seling Co in Central Tibet. From May 1998 to December 2010, the lake level for Seling Co rose from $4533.66 \mathrm{~m}$ to $4543.77 \mathrm{~m}$, with an increasing rate exceeding $0.80 \mathrm{~m} / \mathrm{a}$. However, for these lakes, 
the increasing trends became weaker or even reversed after 2010. The findings were consistent with other previous studies (Hwang et al. 2019; Jiang et al. 2017; Lei et al. 2019; Song et al. 2015b; Yao et al. 2018). However, the lake levels for some lakes, such as Qinghai Lake, Zhari NamCo, Tangra Yumco, Ngangze Co and Migriggyangzham Co, began to increase significantly again after 2016. Among them, the abrupt rise of Zhari NamCo was the most remarkable, with a water level increase during 2016-2018 more than the total during the earlier 16 years (2000-2016). In contrast, the lake level for Nam Co showed inter-annual fluctuations without an evident trend during the recent several years. Level time series of other lakes are provided in the Supplementary Material (Fig. S1).

\section{[Insert Figure 3 here]}

\subsection{Lake level variations based on SARAL and Sentinel-3 altimetry data}

In order to examine whether abrupt water level increase during 2016-2018 occurred similarly in other Tibetan lakes, we investigated the water level changes of a total of 12 lakes from 2013 to 2018 by combining SARAL and Sentinel-3 altimetry data. Six of them were aimed to inter-compare with the Hydroweb and DAHITI altimetry data. Fig. 4 presents the comparisons of water-level time series from Hydroweb/DAHITI data archives and SARAL/Sentinel-3 data between 2013 and 2018 for Qinghai Lake, Nam Co, Ayakkum, Migriggyangzham Co, Zhari NamCo and Tangra YumCo. The water level time series for all the lakes indicate that not only are the general trends derived from two data sources comparable but the abrupt changes and intra-annual variations of lake level are overall consistent. For example, both data sources clearly depict a sudden increase of about $1.0 \mathrm{~m}$ during the wet season (July-September) of 2017 for Zhari NamCo. The characteristics of water levels rises in wet seasons and declines in dry seasons are also in good agreement for all the lakes, suggesting that SARAL and Sentinel-3 data have reliable results.

Based on the above validation, the SARAL and Sentinel-3 data were used to monitor the lakes larger than $100 \mathrm{~km} 2$ in the TP, and the water level time series are shown in Fig. 5. The six lakes display an evident trend of water level increase at varying rates during 2016-2018. For example, the alpine lakes between the Tanggula and Kunlun Mountains, including XijingUlan Lake, Mingjing Lake and UlanUla Lake, showed a significantly rise (exceeding $1 \mathrm{~m} / \mathrm{a}$ ). In contrast, the lake level for Gyariog Co showed an inter-annual fluctuation.

\section{[Insert Figure 4 here]}

\section{[Insert Figure 5 here]}

\subsection{Spatial distribution of lake level changing rates during 2016-2018}

Our results of lake level changing rate are shown in Fig. 6 and Table 3. Obviously, most lakes experienced a significant increase during the period 2016-2018. To be specific, except the lake level of Nam Co remained relatively stable with little fluctuations, the water level time series of other lakes revealed the rising tendency with the mean rate of $0.74 \mathrm{~m} / \mathrm{a}$. The three lakes in the northwestern TP, Jieze Caka, LumajangdongCo, and Heishibei Lake showed significantly difference in water level rising rates, and the level for Heishibei Lake rose fastest, reaching $1.39 \mathrm{~m} / \mathrm{a}$. The northern part of the TP is located in the Hoh Xil region, known for complex and harsh geographical environment. A large number of endorheic lakes are distributed in this region. As listed in Table 3, most of the lakes were expanding with an average level increase of larger than $0.82 \mathrm{~m} / \mathrm{a}$. The level for XijingUlan Lake increased at the greatest rate of $1.52 \mathrm{~m} / \mathrm{a}$. Ayakkum, the largest lake in this region, also exhibited a significant increase of $0.83 \mathrm{~m} / \mathrm{a}$. The average increasing rate was 0.66 $\mathrm{m} / \mathrm{a}$ in the central part of the TP. The lake levels for Dagze Co and Zhari NamCo experienced the rapid rising, exceeding $1 \mathrm{~m} / \mathrm{a}$. In Qinghai Province, the level for Qinghai Lake maintained a steady increasing trend of $0.47 \mathrm{~m} / \mathrm{a}$. Overall, most lakes in the northern Tibetan Plateau experienced a relatively faster rates of water level rise, compared to those in the NETP and eastern CTP.

[Insert Figure 6 here] 


\section{[Insert Table 3 here]}

\subsection{Relationship between lake level changes and precipitation variations}

Since the late 1990s, the expansion of Tibetan lakes has been mainly affected by regional climate changes such as increased water vapor content, potential evaporation reduction and significantly enhanced air convection. (Yang et al. 2014; Yang et al. 2011; Lei et al. 2017; Lu et al. 2015). Therefore, with the acceleration of climate warming and humidification, precipitation could be also gradually increase (Yang et al. 2014), which supports the observation of the rapid lake expansion in the TP.

As shown in Fig. 3 and supplementary materials (Fig. S1), the trends of lake level changes since 1990 are generally consistent with previous studies. Our findings reveal that the drastic water level jumps in Tibetan lakes since 2016, has been a result of continued precipitation increase after a relatively drier period from 2012 to 2016. This suggests that precipitation remains to be a first-order driver of Tibetan lake dynamics. It was found that the drastic increase of lake level in 2017-2018 was consistent with the increase of precipitation in the near past several years, so the monthly precipitation data in recent years was selected and compared with the lake level. According to the study, the monthly precipitation and the lake water level during the period 2013-2018 were selected to study the influence of specific monthly precipitation on the lake water level. The most prominent feature was the good correspondence between lake level increase and the summer precipitation. In addition, we can find that the decrease of water level in individual years (e.g. 2015) corresponded to less summer precipitation. The amplitude of wet season lake level increases showed a good relationship with precipitation amount. For example, the drastic lake level rises in 2017 and 2018 in the TP corresponded to high precipitation. This suggests that the excessive precipitation during the wet season of 2017 and 2018 played a crucial role in the recent lake level increase. Overall, precipitation appears to play a more dominant role than temperature (and its induced glacier/permafrost melting). This was implied by the fact warming-induced melting did not reverse the slow-down or hiatus of lake expansion before 2016 (when precipitation was less), and it would have to be the precipitation increase again that eventually triggered another round of lake level increase. More details on other lakes and meteorological stations can be found in the Supplement (Fig. S2).

\section{[Insert Figure 7 here]}

\subsection{Spatial linkage of increased precipitation to enhanced water vapor circulations}

Previous studies have identified the main sources of moisture for precipitation in the TP, including regions from the Indian sub-continent to the Southern Hemisphere, the Bay of Bengal and the northwestern part of TP. (Chen et al. 2012; Zheng et al. 2019). It is proven that these circulation changes in the increase or decrease of different moisture sources provide favorable water vapor conditions for rainfall on the TP. Thus, the changes in moisture source contributed to different precipitation changes across the entire TP during different periods. As indicated in the preceding results, the lake water levels increased rapidly during the period 2016-2018 relative to the previous stage. The phenomenon was analyzed with the distribution of water vapor transport on the TP.

The differences can be observed with the four years when the water vapor is transported by abnormal northwesterly, southeast wind and south wind in 2015, 2016, 2017 and 2018, respectively (Fig. 8B, Fig. $8 \mathrm{C}$, Fig. 8D, Fig. $8 \mathrm{E}$ ). In comparison, the total water vapor increases with the most significant anomaly in 2017-2018. The moisture transported to the northwestern part of the TP has increased significantly in last several years due to the strengthening of the westerlies. In this study, precipitation in the NTP is more obviously influenced by the East Asian monsoon and the Indian summer monsoon. The summer monsoon circulation was enhanced, and the meridional water vapor transport from the south plateau to the Bay of Bengal was significantly enhanced. Similarly, precipitation in the CTP was more influenced by the Asian summer monsoons. In addition, the water vapor flux from the Indian Ocean to the plateau was enhanced. From Fig. 8D, we can also find that there is a phenomenon of internal water vapor circulation and retention, which might cause water vapor subsidence and significant rainfall over the western CTP. In 
general, the change in water vapor transport during the study period supports the changing characteristics of precipitation and lake level for TP as analyzed above.

In this study, as shown in Fig. 6 and Table 3, we can find the rising rates of lake levels at different parts of TP are different. The water level rising rates for some typical lakes exceed $0.80 \mathrm{~m} / \mathrm{a}$ in the northern TP such as XijingUlan Lake, Mingjing Lake, Lexiewudan and Ayakkum. There are some glaciers distributed in the northern TP, and there is rich rainfall in the rainy season. Therefore, the rapid increase of water level is affected by both rainfall and glacial meltwater. The rising rate of lake level in central TP is mainly divided into two categories. For example, at Zhari Namco and Dagze Co in the western CTP, the rising rates are $1.34 \mathrm{~m} / \mathrm{a}$ and $1.43 \mathrm{~m} / \mathrm{a}$ respectively. The rising rates of lakes in the central and eastern CTP are slower, generally less than $0.40 \mathrm{~m} / \mathrm{a}$. The reason for this difference may be because the phenomenon of internal water vapor circulation and retention mainly occur in the western CTP. In NWTP which was mainly affected by the westerlies, the distinction in water vapor transport distribution in different years led to a significant difference in the water level rising rates. As indicated in the preceding texts, the differences in water level rise rate are caused by different water vapor transport patterns and main sources in different regions.

\section{[Insert Figure 8 here]}

\subsection{Associations of TP lake level and precipitation changes with El Nino/La Nina events}

We further found the potential associations of lake and precipitation variations on the TP with El Nino and La Nina events, as illustrated in Fig. 9, S3 and S4. In the CTP, considerable expansion can be found at Zhari NamCo, Tangra YumCo and Seling Co during the 2016/2017 and 2017/2018 La Nina events, corresponding well with excessive precipitation in these two years. On the NTP, dramatic expansions can also be found at Dogai Coring Lake and Lexiewudan Lake during the 2016/2017 and 2017/2018 La Nina events (Fig. S4). The expansion of Zhari NamCo was also remarkable due to the dramatic precipitation increase likely driven by La Nina. Despite some exceptions, we can see that drastic lake expansion in the TP is very consistent with historical La Nina incidents, which indicates that La Nina events may exert evident impact on the hydroclimate of the TP. In addition to ENSO, other climate variabilities (e.g., the North Atlantic Oscillation, Arctic Oscillation, and the Indian Ocean Dipole) may also promote the lake expansion in the TP (Liu and Juarez 2001; Wang et al. 2008). In contrast, considerable lake shrinkage (in 2011 and 2015) occurred in the TP during El Nino events (Lei et al. 2019). We here found a phenomenon that is different from the results of previous studies. In NTP, the lake level changes have drastically increased relative to 2015 (El Nino event) during the 2016/2017 and 2017/2018 La Nina events (Fig. S4), whereas the teleconnection between lake dynamics and La Nina appears weaker in NWTP. The three selected lakes (LumajangdongCo, Jieze Caka and Heishibei Lake) in NWTP expanded steadily even in 2015, but lake expansion was more dramatic in 2016 and 2017 (Fig. 5 and Fig. S1). This continuous lake expansion is dominated by lake dynamics in NWTP as reported in previous study (Jiang et al. 2017; Kleinherenbrink et al. 2015; Lei et al. 2017). Since glaciers are widely distributed in NWTP, the contribution of glacier melt to lake level change may be greater than the impact of the La Nina event. As indicated above, water level changes of different lakes showed different spatial and temporal patterns due to the obvious spatial heterogeneity of climate change. This anomaly rainfall change is closely associated with El Nino/La Nina event or other atmospheric circulation events.

\section{[Insert Figure 9 here]}

\section{Conclusions}

The more recent studies benefiting from the longer and finer observations revealed the growth tendency of lakes in the central TP had been decelerated or reversed during the period 2010-2016. However, whether the deceleration or hiatus would last in the following years remains unclear. It has not been systematically investigated thus far. Thus, in this study, 22 large inland lakes were investigated to update our understanding of the changing characteristics of Tibetan lakes during the period 2016-2018 by combining the traditional 
and recently-advanced radar altimetry measurements. Furthermore, we will explore the potential climate driving mechanism of the recent varying tendency of lake changes in the TP. For most lakes in the TP, lake levels showed an abrupt rise during 2016-2018, compared with the earlier stage during 2010-2016, but the onsets and magnitudes of water level rise varied with subzones and lakes.

Our results reveal that the lake water levels in the NTP displayed a sharply rise with an average rate of $0.90 \mathrm{~m} / \mathrm{a}$ except Kusai Lake (outburst of its upstream lake). In the central TP, the lake level changes are divided into two categories during the period 2016-2018, which is different from the dramatic increasing pattern for lakes in the northern TP. The water level for Qinghai Lake in the northeastern TP kept a stable growth tendency during the recent years, reaching $0.47 \mathrm{~m} / \mathrm{a}$. The water level rising rates for the three lakes in the northwestern TP (LumajangdongCo, Jieze Caka and Heishibei Lake) are extremely different from each other. The spatial differences of the lake level rise rates were primarily caused by the changes of precipitation over the TP, which may be related to the large-scale atmospheric circulation. The atmospheric circulations such as ENSO and AO may contribute to the anomalous precipitation by driving water vapor transport of TP, but vary with different years. Although this study could be beneficial for our understanding of the driving mechanism of the rapid water level rise of Tibetan lakes and hydrological cycle under future climate change conditions, more comprehensive investigations of precise physical processes are required to clarify the climate-driven mechanism of Tibetan lake level changes in the further study.Acknowledgments:

This work was partly funded by the Second Tibetan Plateau Scientific Expedition and Research (2019QZKK0202), the Strategic Priority Research Program of the Chinese Academy of Sciences (Grant No. XDA23100102), the National Key Research and Development Program of China (Grant No. 2019YFA0607101, 2018YFD0900804, 2018YFD1100101), the Thousand Young Talents Program in China (Grant No. Y7QR011001), and the National Natural Science Foundation of China (No. 41971403, 41801321). We are also grateful to the Laboratoire d'Etudes en Geophysique et Oceanographie Spatiales (LEGOS), the Hydrological Time Series of Inland Waters (DAHITI), the NASA EOSDIS Physical Oceanography Distributed Active Archive Center (PO.DAAC), Centre National d'Etudes Spatiales (CNES), the China Meteorological Data Sharing Service System and the European Centre for Medium-Range Weather Forecasts for providing satellite altimetry data and meteorological data for this study.

\section{Data Availability Statement}

Hydroweb data and DAHITI data are downloaded from the Hydroweb service (http://hydroweb.theialand.fr) and the DAHITI service (https://dahiti.dgfi.tum.de/en), respectively. We can download the SARAL data from ftp://avisoftp.cnes.fr and Sentinel-3 data from https://sentinel.esa.int/web/sentinel/sentineldata-access. The precipitation data and ERA-interim reanalysis data are collected from the China Meteorological Network (http://data. cma.cn) and the NOAA Physical Sciences Laboratory (https://psl.noaa.gov/data/gridded/data.erainterim.html).

\section{Reference}

Busker, T., de Roo, A., Gelati, E., Schwatke, C., Adamovic, M., Bisselink, B., Pekel, J.-F., \& Cottam, A. (2019). A global lake and reservoir volume analysis using a surface water dataset and satellite altimetry. Hydrology and Earth System Sciences, 23 , 669-690

Chen, B., Xu, X.-D., Yang, S., \& Zhang, W. (2012). On the origin and destination of atmospheric moisture and air mass over the Tibetan Plateau. Theoretical and Applied Climatology, 110 , 423-435

Cretaux, J.-F., Calmant, S., Romanovski, V., Perosanz, F., Tashbaeva, S., Bonnefond, P., Moreira, D., Shum, C., Nino, F., \& Berge-Nguyen, M. (2011a). Absolute calibration of Jason radar altimeters from GPS kinematic campaigns over Lake Issykkul. Marine Geodesy, 34 , 291-318

Cretaux, J.-F., Calmant, S., Romanovski, V., Shabunin, A., Lyard, F., Berge-Nguyen, M., Cazenave, A., Hernandez, F., \& Perosanz, F. (2009). An absolute calibration site for radar altimeters in the continental domain: Lake Issykkul in Central Asia. Journal of Geodesy, 83 , 723-735 
Cretaux, J.-F., Jelinski, W., Calmant, S., Kouraev, A., Vuglinski, V., Berge-Nguyen, M., Gennero, M.-C., Nino, F., Del Rio, R.A., \& Cazenave, A. (2011b). SOLS: A lake database to monitor in the Near Real Time water level and storage variations from remote sensing data. Advances in space research, 47, 1497-1507

Dee, D.P., Uppala, S.M., Simmons, A., Berrisford, P., Poli, P., Kobayashi, S., Andrae, U., Balmaseda, M., Balsamo, G., \& Bauer, d.P. (2011). The ERA-Interim reanalysis: Configuration and performance of the data assimilation system. Quarterly Journal of the royal meteorological society, 137 , 553-597

Donchyts, G., Eilander, D., Schellekens, J., Winsemius, H., Gorelick, N., Erickson, T., \& Van De Giesen, N. (2016). Monitoring Earth's reservoir and lake dynamics from space. In, AGU Fall Meeting Abstracts

Donlon, C., Berruti, B., Buongiorno, A., Ferreira, M.-H., Femenias, P., Frerick, J., Goryl, P., Klein, U., Laur, H., \& Mavrocordatos, C. (2012). The global monitoring for environment and security (GMES) sentinel-3 mission. Remote Sensing of Environment, 120 , 37-57

Gao, L., Liao, J., \& Shen, G. (2013). Monitoring lake-level changes in the Qinghai-Tibetan Plateau using radar altimeter data (2002-2012).Journal of Applied Remote Sensing, 7, 073470

Huang, S., Dahal, D., Young, C., Chander, G., \& Liu, S. (2011). Integration of Palmer Drought Severity Index and remote sensing data to simulate wetland water surface from 1910 to 2009 in Cottonwood Lake area, North Dakota. Remote Sensing of Environment, 115 , 3377-3389

Hwang, C., Cheng, Y.-S., Yang, W.-H., Zhang, G., Huang, Y.-R., Shen, W.-B., \& Pan, Y. (2019). Lake level changes in the Tibetan Plateau from Cryosat-2, SARAL, ICESat, and Jason-2 altimeters. Terr. Atmos. Ocean Sci, 30 , 1-18

Jarihani, A.A., Callow, J.N., Johansen, K., \& Gouweleeuw, B. (2013). Evaluation of multiple satellite altimetry data for studying inland water bodies and river floods. Journal of Hydrology, 505 , 78-90

Jiang, L., Nielsen, K., Andersen, O.B., \& Bauer-Gottwein, P. (2017). Monitoring recent lake level variations on the Tibetan Plateau using CryoSat-2 SARIn mode data. Journal of hydrology, 544, 109-124

Jiang, L., Andersen, O. B., Nielsen, K., Zhang, G., \& Bauer-Gottwein, P. (2019). Influence of local geoid variation on water surface elevation estimates derived from multi-mission altimetry for Lake Namco.Remote Sensing of Environment, 221, 65-79.

Kleinherenbrink, M., Lindenbergh, R., \& Ditmar, P. (2015). Monitoring of lake level changes on the Tibetan Plateau and Tian Shan by retracking Cryosat SARIn waveforms. Journal of hydrology, 521 , 119-131

Lehner, B., \& Doll, P. (2004). Development and validation of a global database of lakes, reservoirs and wetlands. Journal of Hydrology, $296,1-22$

Lei, Y., Yang, K., Wang, B., Sheng, Y., Bird, B.W., Zhang, G., \& Tian, L. (2014). Response of inland lake dynamics over the Tibetan Plateau to climate change. Climatic change, 125, 281-290

Lei, Y., Yao, T., Yang, K., Sheng, Y., Kleinherenbrink, M., Yi, S., Bird, B.W., Zhang, X., Zhu, L., \& Zhang, G. (2017). Lake seasonality across the Tibetan Plateau and their varying relationship with regional mass changes and local hydrology. Geophysical Research Letters, 44 , 892-900

Lei, Y., Zhu, Y., Wang, B., Yao, T., Yang, K., Zhang, X., Zhai, J., \& Ma, N. (2019). Extreme lake level changes on the Tibetan Plateau associated with the 2015/2016 El Nino. Geophysical Research Letters, 46 , 5889-5898

Liu, W., \& Juarez, R.N. (2001). ENSO drought onset prediction in northeast Brazil using NDVI. International Journal of Remote Sensing, 22 , 3483-3501

Lu, N., Trenberth, K.E., Qin, J., Yang, K., \& Yao, L. (2015). Detecting long-term trends in precipitable water over the Tibetan Plateau by synthesis of station and MODIS observations. Journal of Climate, 28, $1707-1722$ 
Lu, S., Jia, L., Zhang, L., Wei, Y., Baig, M.H.A., Zhai, Z., Meng, J., Li, X., \& Zhang, G. (2017). Lake water surface mapping in the Tibetan Plateau using the MODIS MOD09Q1 product. Remote sensing letters, 8 , 224-233

Ma, R., Duan, H., Hu, C., Feng, X., Li, A., Ju, W., Jiang, J., \& Yang, G. (2010). A half-century of changes in China's lakes: Global warming or human influence? Geophysical Research Letters, 37

Mao, D., Wang, Z., Yang, H., Li, H., Thompson, J.R., Li, L., Song, K., Chen, B., Gao, H., \& Wu, J. (2018). Impacts of climate change on Tibetan lakes: Patterns and processes. Remote Sensing, 10 , 358

Palmer, S.C., Kutser, T., \& Hunter, P.D. (2015). Remote sensing of inland waters: Challenges, progress and future directions. In: Elsevier

Pekel, J.-F., Cottam, A., Gorelick, N., \& Belward, A.S. (2016). High-resolution mapping of global surface water and its long-term changes. Nature, 540 , 418-422

Phan, V., Lindenbergh, R., \& Menenti, M. (2012). Seasonal trends in Tibetan lake level changes as observed by ICESat laser altimetry.ISPRS Annals of the Photogrammetry, Remote Sensing and Spatial Information Sciences, 1 , 237-242

Piao, S., Cui, M., Chen, A., Wang, X., Ciais, P., Liu, J., \& Tang, Y. (2011). Altitude and temperature dependence of change in the spring vegetation green-up date from 1982 to 2006 in the Qinghai-Xizang Plateau. Agricultural and Forest Meteorology, 151, 1599-1608

Project, J.M.M. (2010). GHRSST Level 4 MUR Global Foundation Sea Surface Temperature Analysis

Qiao, B., Zhu, L., \& Yang, R. (2019). Temporal-spatial differences in lake water storage changes and their links to climate change throughout the Tibetan Plateau. Remote sensing of environment, 222 , 232-243

Schwatke, C., Dettmering, D., Bosch, W., \& Seitz, F. (2015). DAHITI-an innovative approach for estimating water level time series over inland waters using multi-mission satellite altimetry. Hydrology and Earth System Sciences, 19 , 4345-4364

Sheng, Y., Song, C., Wang, J., Lyons, E.A., Knox, B.R., Cox, J.S., \& Gao, F. (2016). Representative lake water extent mapping at continental scales using multi-temporal Landsat-8 imagery. Remote sensing of environment, $185,129-141$

Shi, K., Zhang, Y., Liu, X., Wang, M., \& Qin, B. (2014). Remote sensing of diffuse attenuation coefficient of photosynthetically active radiation in Lake Taihu using MERIS data. Remote Sensing of Environment, $140,365-377$

Smith, L.C., Sheng, Y., MacDonald, G., \& Hinzman, L. (2005). Disappearing arctic lakes. Science, 308 , $1429-1429$

Song, C., Huang, B., \& Ke, L. (2013). Modeling and analysis of lake water storage changes on the Tibetan Plateau using multi-mission satellite data. Remote sensing of environment, 135 , 25-35

Song, C., Huang, B., Ke, L., \& Richards, K.S. (2014a). Remote sensing of alpine lake water environment changes on the Tibetan Plateau and surroundings: A review. ISPRS Journal of Photogrammetry and Remote Sensing, 92, 26-37

Song, C., Huang, B., Richards, K., Ke, L., \& Hien Phan, V. (2014b). Accelerated lake expansion on the Tibetan Plateau in the 2000s: Induced by glacial melting or other processes? Water Resources Research, 50 , 3170-3186

Song, C., Ye, Q., \& Cheng, X. (2015a). Shifts in water-level variation of Namco in the central Tibetan Plateau from ICESat and CryoSat-2 altimetry and station observations. Science Bulletin, 60 , 1287-1297

Song, C., Ye, Q., Sheng, Y., \& Gong, T. (2015b). Combined ICESat and CryoSat-2 altimetry for accessing water level dynamics of Tibetan lakes over 2003-2014. Water, 7 , 4685-4700 
Vorosmarty, C.J. (2002). Global water assessment and potential contributions from Earth Systems Science. Aquatic Sciences, 64 , 328-351

Wan, W., Long, D., Hong, Y., Ma, Y., Yuan, Y., Xiao, P., Duan, H., Han, Z., \& Gu, X. (2016). A lake data set for the Tibetan Plateau from the 1960s, 2005, and 2014. Scientific data, 3, 1-13

Wang, J., Sheng, Y., \& Tong, T.S.D. (2014). Monitoring decadal lake dynamics across the Yangtze Basin downstream of Three Gorges Dam.Remote Sensing of Environment, 152 , 251-269

Wang, J., Song, C., Reager, J.T., Yao, F., Famiglietti, J.S., Sheng, Y., MacDonald, G.M., Brun, F., Schmied, H.M., \& Marston, R.A. (2018). Recent global decline in endorheic basin water storages. Nature Geoscience, $11,926-932$

Wang, L., Chen, W., \& Huang, R. (2008). Interdecadal modulation of PDO on the impact of ENSO on the East Asian winter monsoon.

Geophysical Research Letters, 35

Wang, X., Gong, P., Zhao, Y., Xu, Y., Cheng, X., Niu, Z., Luo, Z., Huang, H., Sun, F., \& Li, X. (2013). Water-level changes in China's large lakes determined from ICESat/GLAS data. Remote sensing of environment, 132, 131-144

Xu, Z., Gong, T., \& Li, J. (2008). Decadal trend of climate in the Tibetan Plateau-regional temperature and precipitation.Hydrological Processes: An International Journal, 22 , 3056-3065

Yang, K., Wu, H., Qin, J., Lin, C., Tang, W., \& Chen, Y. (2014). Recent climate changes over the Tibetan Plateau and their impacts on energy and water cycle: A review. Global and Planetary Change, 112, 79-91

Yang, K., Ye, B., Zhou, D., Wu, B., Foken, T., Qin, J., \& Zhou, Z. (2011). Response of hydrological cycle to recent climate changes in the Tibetan Plateau. Climatic change, 109 , 517-534

Yao, F., Wang, J., Wang, C., \& Cretaux, J.-F. (2019). Constructing long-term high-frequency time series of global lake and reservoir areas using Landsat imagery. Remote Sensing of Environment, 232 , 111210

Yao, F., Wang, J., Yang, K., Wang, C., Walter, B.A., \& Cretaux, J.-F. (2018). Lake storage variation on the endorheic Tibetan Plateau and its attribution to climate change since the new millennium.

Environmental Research Letters, 13

Zhang, G., Luo, W., Chen, W., \& Zheng, G. (2019). A robust but variable lake expansion on the Tibetan Plateau. Science Bulletin, 64, 1306-1309

Zhang, G., Xie, H., Kang, S., Yi, D., \& Ackley, S.F. (2011). Monitoring lake level changes on the Tibetan Plateau using ICESat altimetry data (2003-2009). Remote sensing of environment, 115 , 1733-1742

Zhang, G., Yao, T., Xie, H., Zhang, K., \& Zhu, F. (2014). Lakes' state and abundance across the Tibetan Plateau. Chinese Science Bulletin, 59 , 3010-3021

Zheng, G., Bao, A., Li, J., Zhang, G., Xie, H., Guo, H., Jiang, L., Chen, T., Chang, C., \& Chen, W. (2019). Sustained growth of high mountain lakes in the headwaters of the Syr Darya River, Central Asia. Global and Planetary Change, 176, 84-99

Zhu, L., Xie, M., \& Wu, Y. (2010). Quantitative analysis of lake area variations and the influence factors from 1971 to 2004 in the Nam Co basin of the Tibetan Plateau. Chinese Science Bulletin, 55 , 1294-1303

\section{Hosted file}

Table1.docx available at https://authorea.com/users/335715/articles/461532-recent-abnormalhydrologic-behavior-of-tibetan-lakes-inferred-from-multi-mission-altimetry-and-itsdriving-force-analyses 


\section{Hosted file}

Table2.docx available at https://authorea.com/users/335715/articles/461532-recent-abnormalhydrologic-behavior-of-tibetan-lakes-inferred-from-multi-mission-altimetry-and-itsdriving-force-analyses

\section{Hosted file}

Table3.docx available at https://authorea.com/users/335715/articles/461532-recent-abnormalhydrologic-behavior-of-tibetan-lakes-inferred-from-multi-mission-altimetry-and-itsdriving-force-analyses
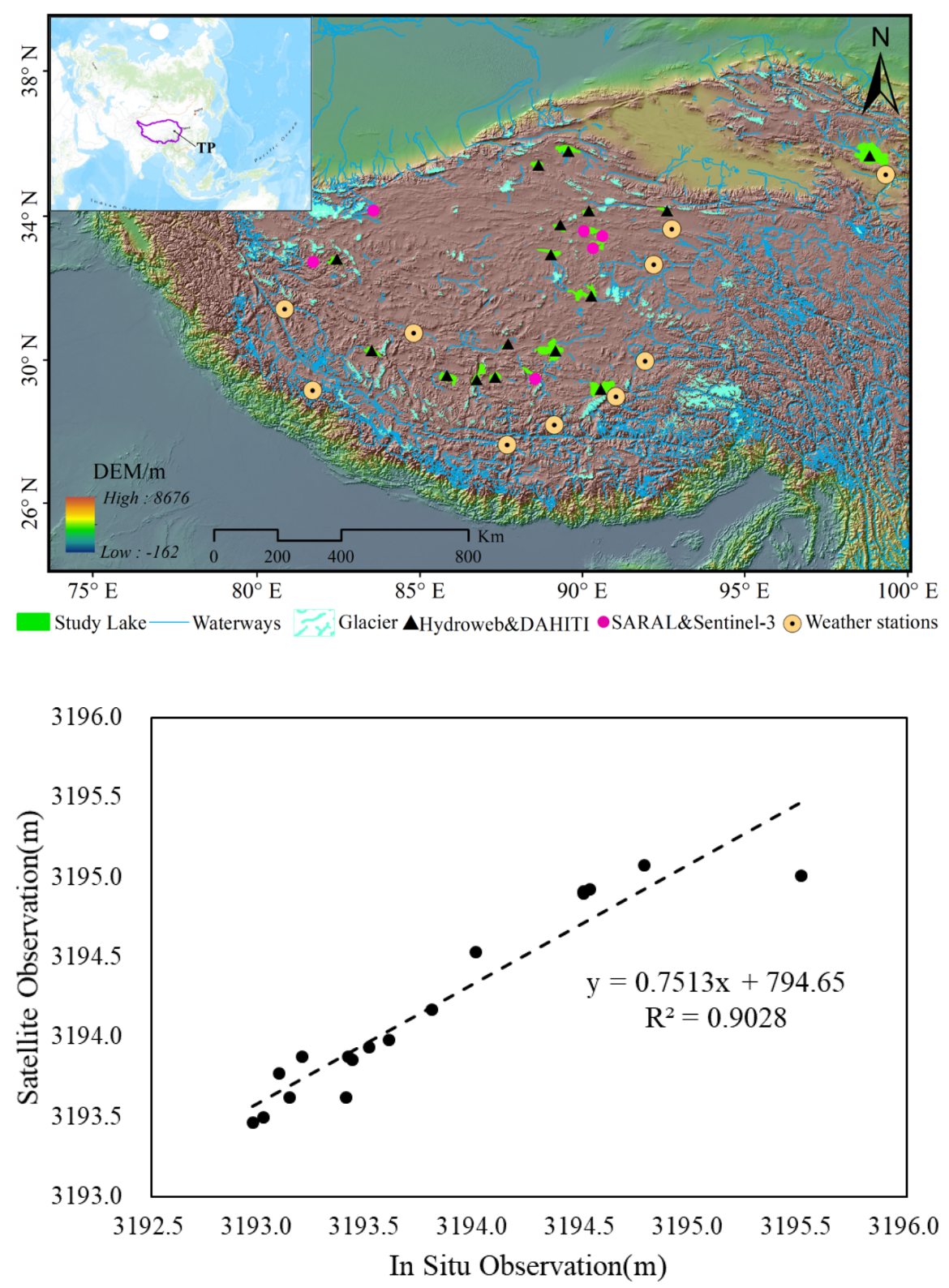

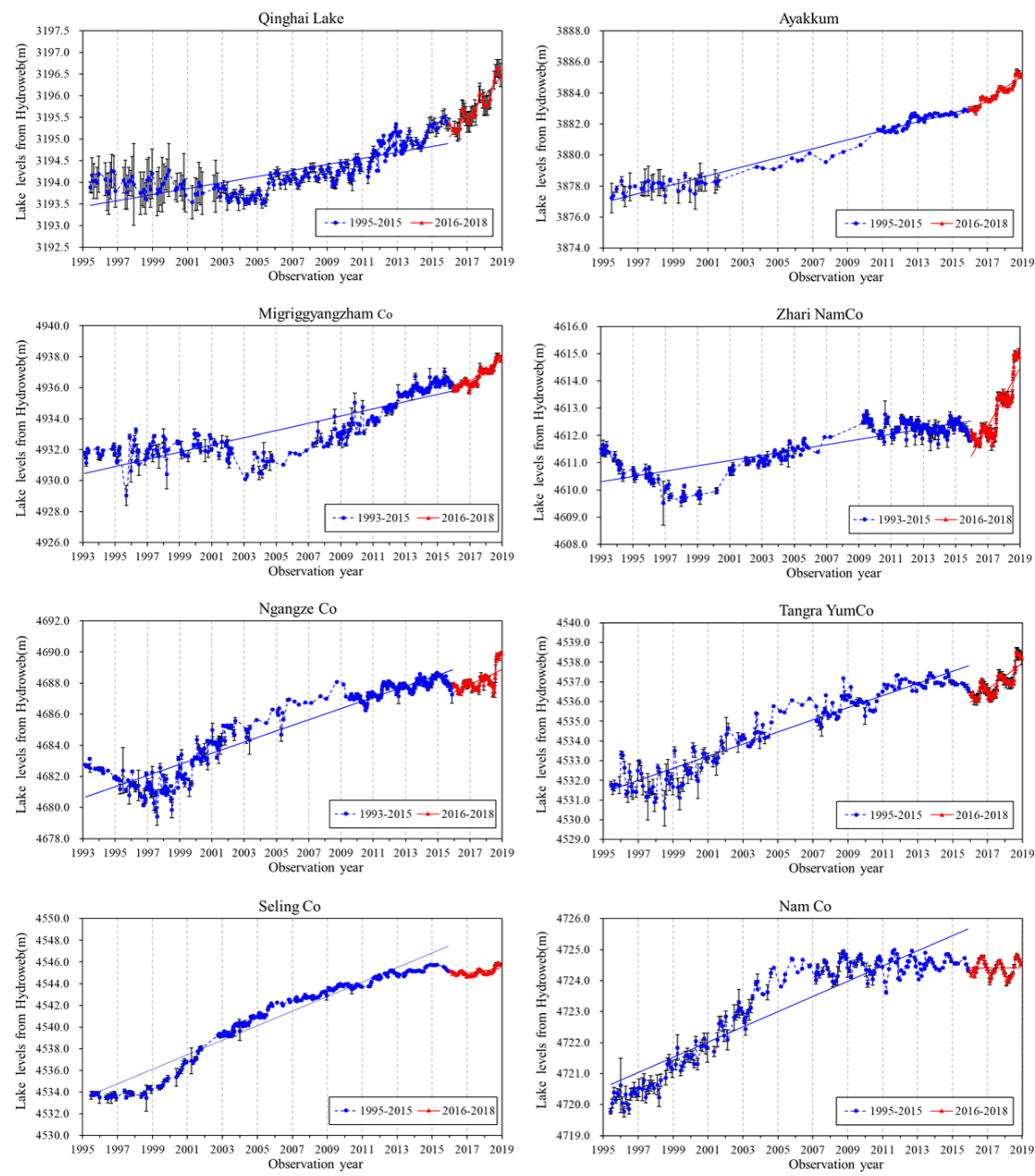

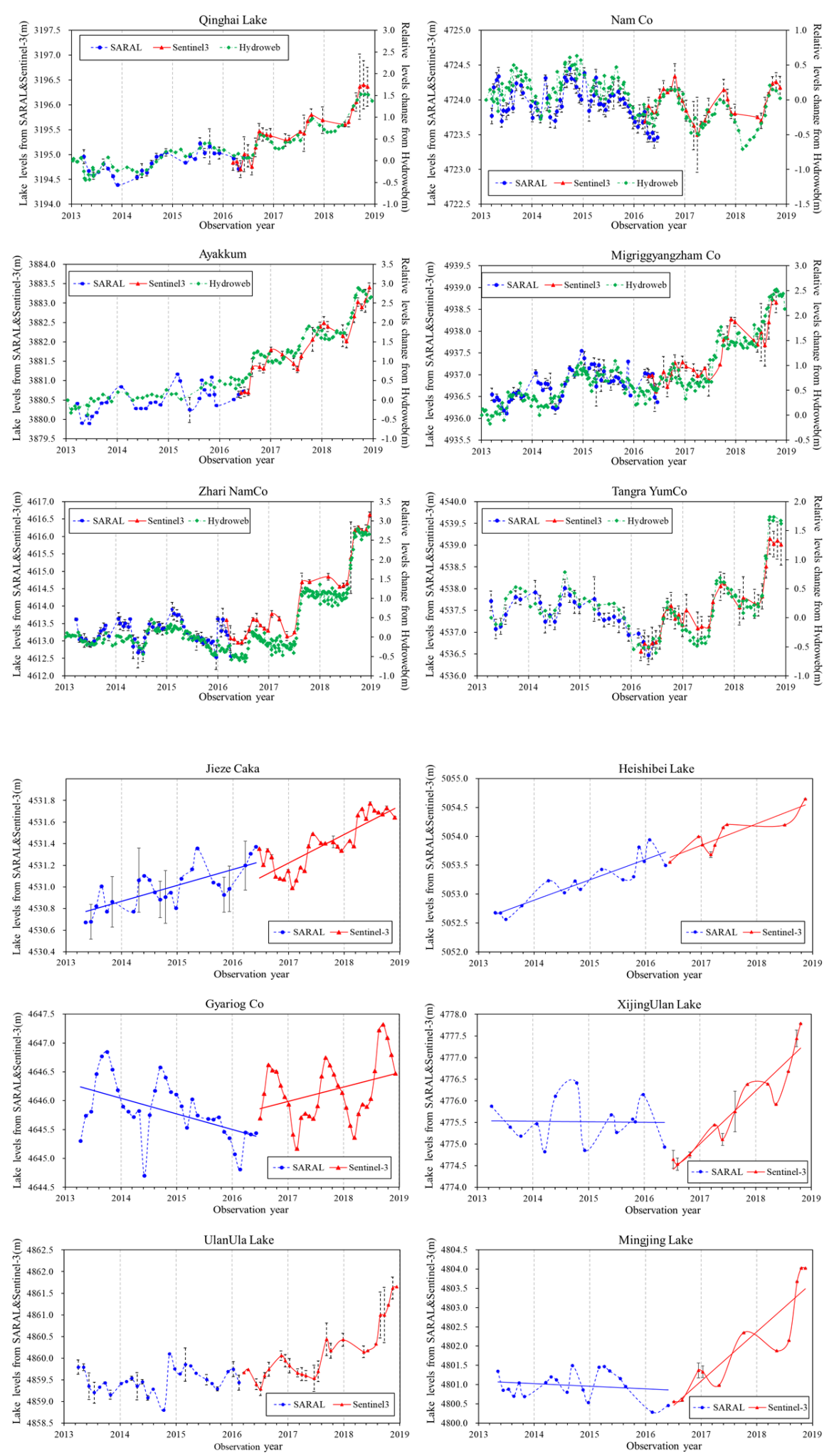


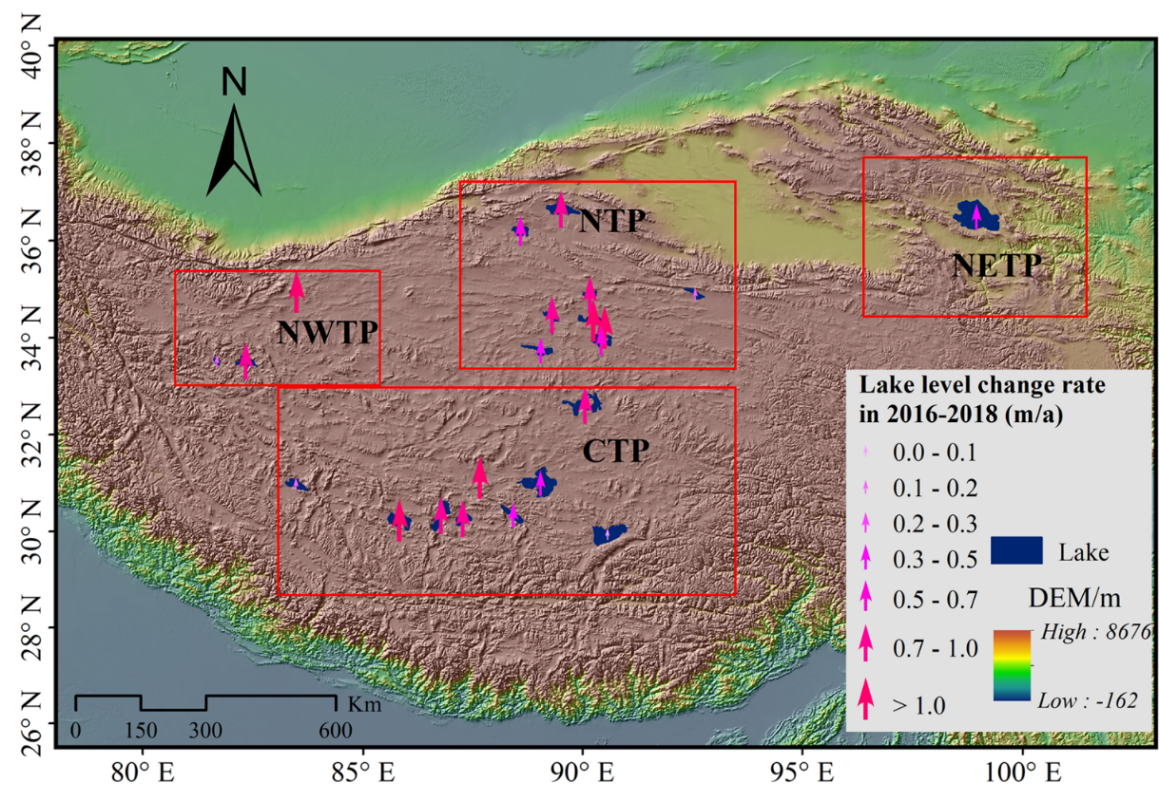




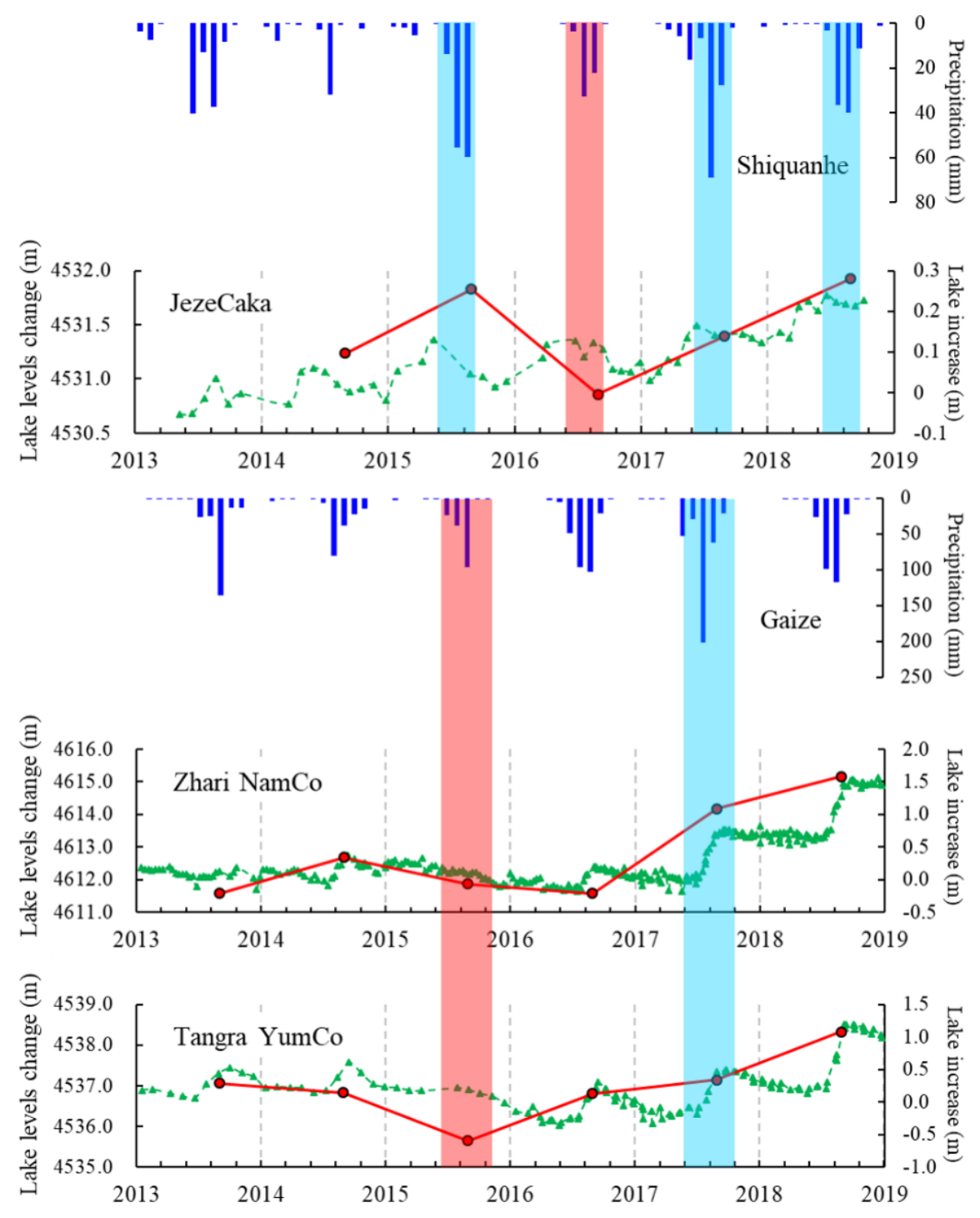




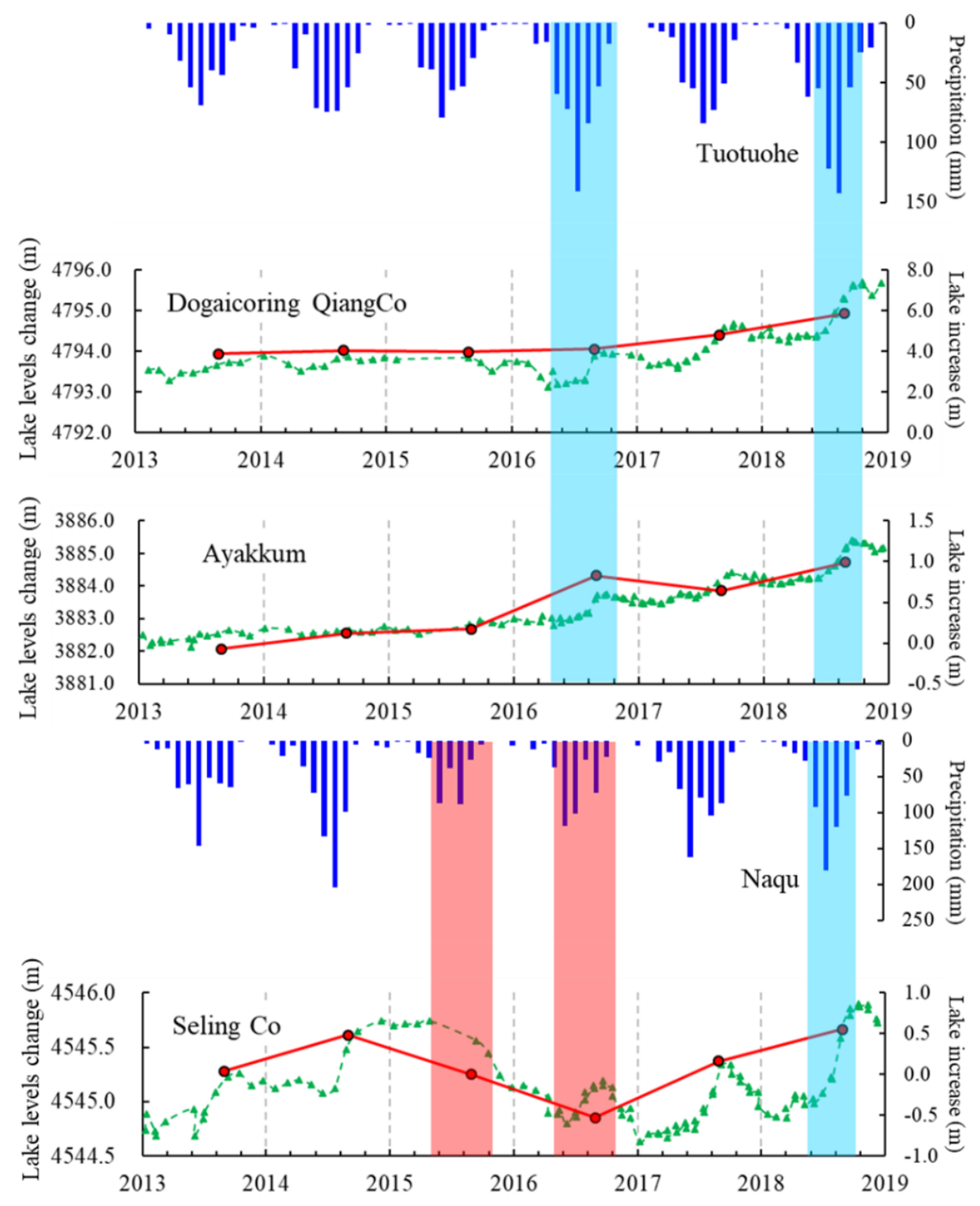



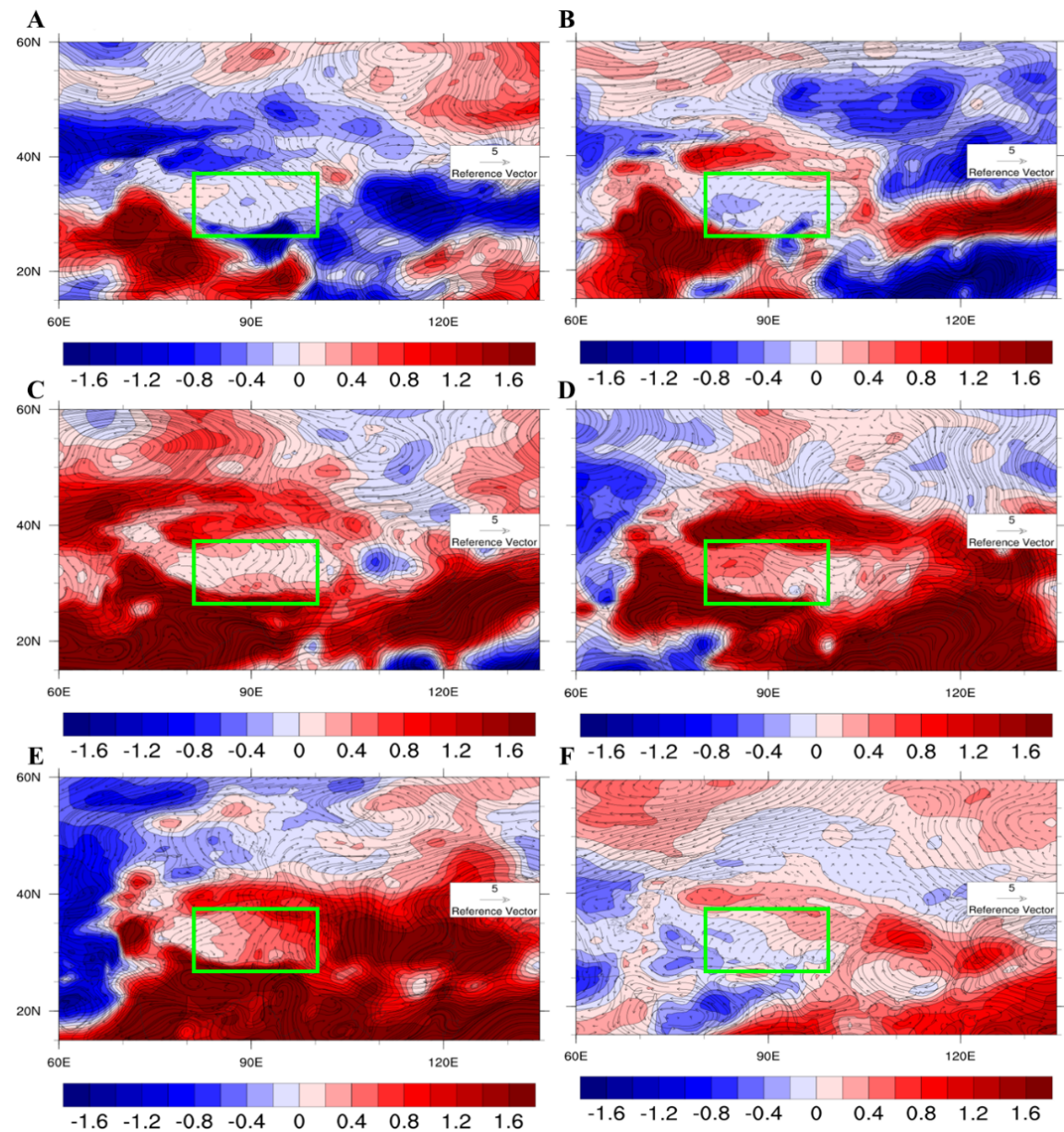

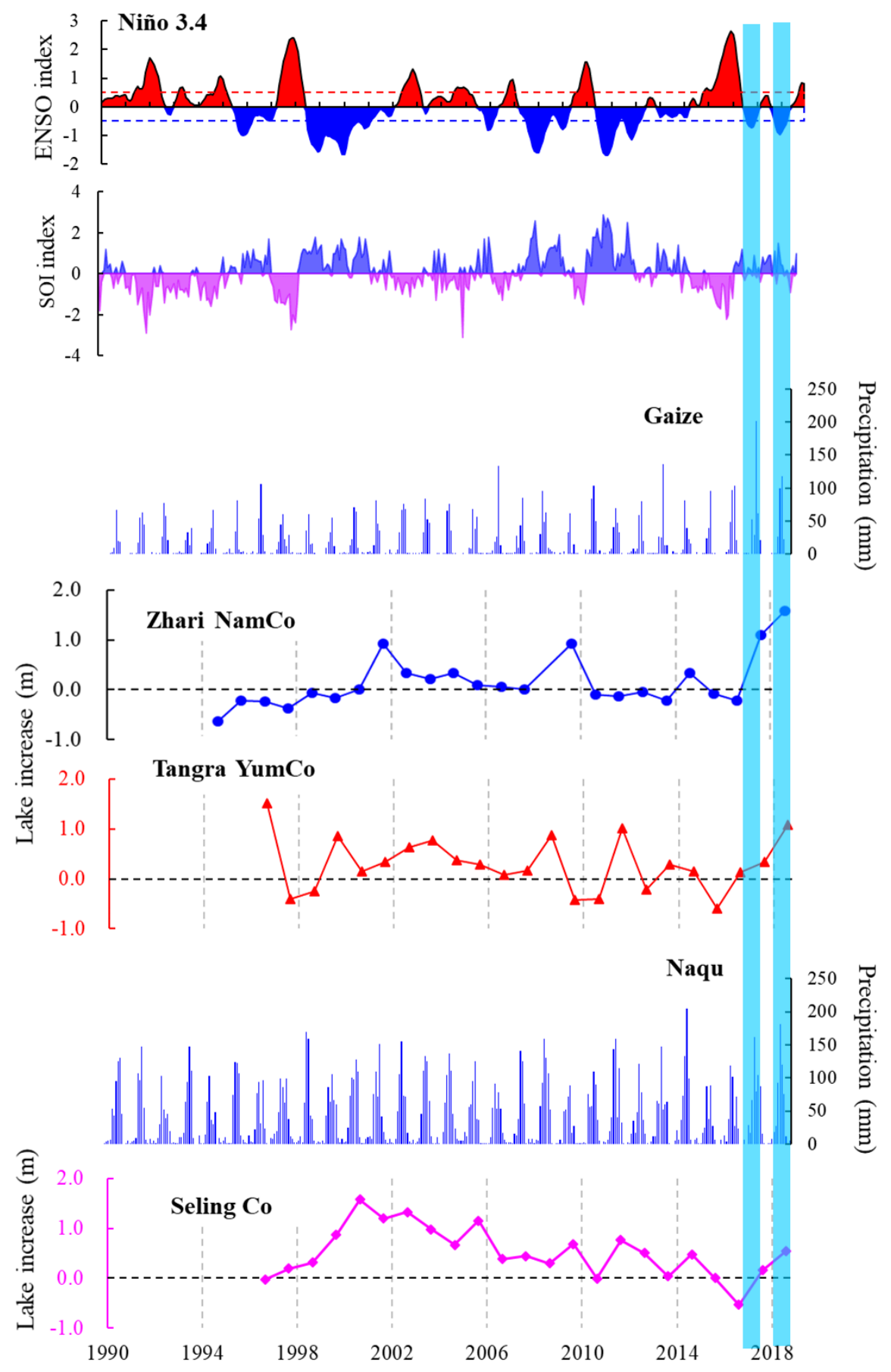